\title{
High-Temperature Compatibility Study of Iridium (DOP-26 Alloy) \\ with Graphite and Plutonia
}

\author{
K. M. Axler
}

D. T. Eash






\title{
HIGH-TEMPERATURE COMPATIBLLITY STUDY OF IRIDIUM (DOP-26 ALLOY) WITH GRAPHITE AND PLUTONIA
}

by

K. M. Axler and D. T. Eash

\begin{abstract}
This report outlines the materials compatibility tests conducted on DOP-26 iridium alloy and carbon. The carbon used was in the form of woven graphite as present in the impact shelI used to encase plutonia in nuclear heat sources. In addition, compatibility tests of the DOP-26 alloy with plutonia are described. The regctivity observed in both systems is discussed.
\end{abstract}

\section{INTRODUCTION}

This work was conducted as part of a test program to investigate materials compatibility in nuclear heat sources. The units under investigation are those composing the General Purpose Heat Source (GPHS). The self-heating effect of the ${ }^{238} \mathrm{PuO}_{2}$ fuel in the GPHS provides thermal energy, which is converted to electrical power via Radioisotope Thermoelectric Generators (RTGs). RTGs can supply electric power for more than 20 years and are used in various space applications.

The ${ }^{238} \mathrm{PuO}_{2}$ heat sources are designed tc perate at temperatures on the order of $1200^{\circ} \mathrm{C}-1300^{\circ} \mathrm{C}$. However, higher temperature phase studies are conducted to characterize materials compatibility in the event of an accidental temperature excursion. These temperature excursions might be induced by an explosion or fire or by aerodynamic heating during accidental reentry in to the earth's atmosphere.

In the GPHS, $\mathrm{PuO}_{2}$ is contained within a cladding of iridium-based DOP-26 alloy. This alloy contains 0.3-0.5 wt.\% tungsten and trace amounts of aluminum and thorium. In service, a protective graphite impact shell (GIS) of fineweave-pierced fabric (FWPF) graphite (AVCO Systems Division) surrounds the GPHS cladding.

\section{I. DOP-26/GRAPHITE}

\section{A. Experimental Procedure}

A series of induction heatings was conducted to determine the minimum reaction temperature for carbon (as woven graphite) and DOP-26. Specifically, we wanted to determine if contact with the GIS would induce a low-melting eutectic-like reaction with the heat source cladding.

Shards of DOP-26 were placed within crucibles fabricated from the same FWPF used in the GIS. The graphite cells were separated from the yttria stage of the induction heater by tungsten foil. The material was heated for 15 minutes at progressively higher temperatures. Temperatures were read with an optical 
pyromete- ghting on the sample surface through a black-body hole in the cell lid. The reported temperatures reflect a correction factor for window attenuation. Between each consecutive heating, the sample was visually examined for signs of reaction and was also checked for weight loss. After consecutive heatings to $2283^{\circ} \mathrm{C}$. there was no evidence of reaction or liquification. and no weight loss had occurred. Upon the next heating. to $2360^{\circ} \mathrm{C}$, the sample showed signs of melting. No weight loss was observed. $A$ cross section was cut from the product and prepared for electron microprobe examination.

\section{B. Observations}

The mounted specimen was found to contain two phases distributed throughout its depth. Figure 1 shows a secondary electron image of a typical region with a corresponding $x$-ray dot map for carbon. The



Fig. 1a. Secondary electron image of carbon platelets (400X).

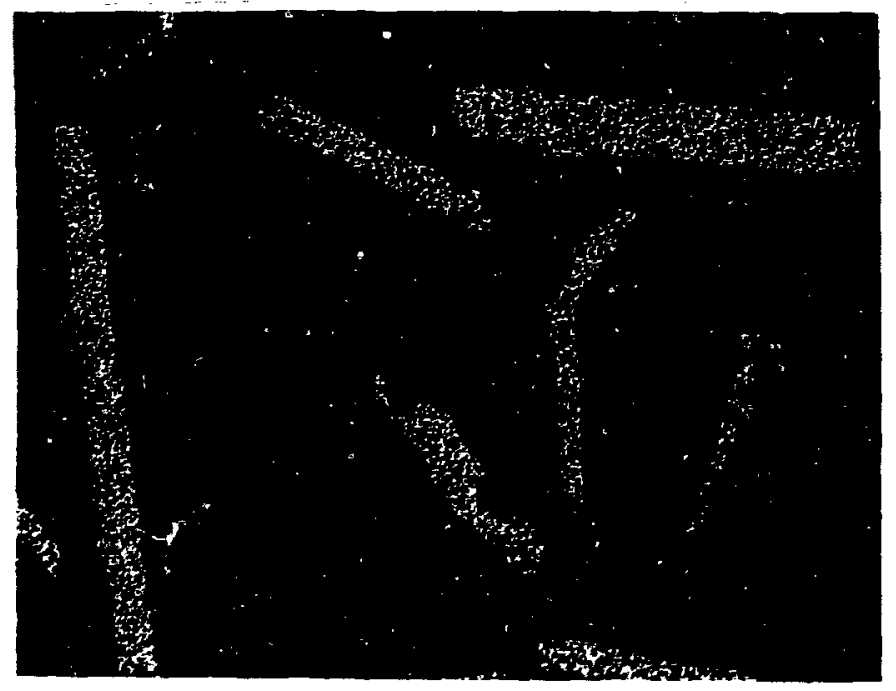

Fig. 1b. X-ray dot map for carbon $(40) \times)$. 
major component of the specimen was an iridium matrix of the nominal DOP-26 composition. The secondary phase consisted of large platelets of carbon dispersed throughout the specimen and a distribution of extremely fine carbon striations within the matrix. The carbon-rich platelets contained $\sim 0.2$ at.\% iridium. No carbon was detected in the matrix. Figure 2 shows a typical boundary between a platelet and the matrix. The superımposed $x$-ray intensity lines illustrate the absence of a compositional gradient at the interface region.

\section{Discussion and Conclusions}

According to Moissan. ' carbon dissolves in pure iridium liquid, but it is precipitated out as graphite upon cooling. Our observations are in agreement with this previously published work. In our study, the absence of dissolved carbon within the DOP-26 matrix indicates that the solid solubility for carbon in iridium is negligible at room temperature. However, the finely distributed striations appear to have grown out of the melt and indicate a larger solubility at elevated temperatures. (The large carbon inclusions may be artifacts of loosely woven graphite picked up by the melt.)

These observations are consistent with the Ir-C phase diagram² shown in Fig. 3. According to the Ir-C phase diagram, the melting point for iridium with $3.12 \%$ dissolved carbon is $2296 \pm 16^{\circ} \mathrm{C}$. The specimen showed signs of melting within this temperature range, which indicates a melting point depression associated with dissolved carbon. The melting point for the DOP-26 alloy is approximately $2447^{\circ} \mathrm{C}$ (based on the melting point of iridium ${ }^{3}$ ).

The study has indicated that the liquification of DOP-26 is affected by contact with the GIS material in agreement with the $\mathrm{Ir}-\mathrm{C}$ phase diagram.

\section{iI. $\mathrm{DOP}-26 / \mathrm{PuO}_{2}$}

\section{A. Experimental Procedure}

The initial test involved reacting DOP-26 with $\mathrm{PuO}_{2}$ powder by arc melting. The starting composition was $\sim 50$ vol\% $\mathrm{PuO}_{2}$. The reactants were combined and pressed into a pellet at $\sim 100,000 \mathrm{psi}$. The



Fig. 2. Secondary electron image of a platelet/matrix interface with superimposed $x$-ray intensity lines for carbon and iridium (2000X). 


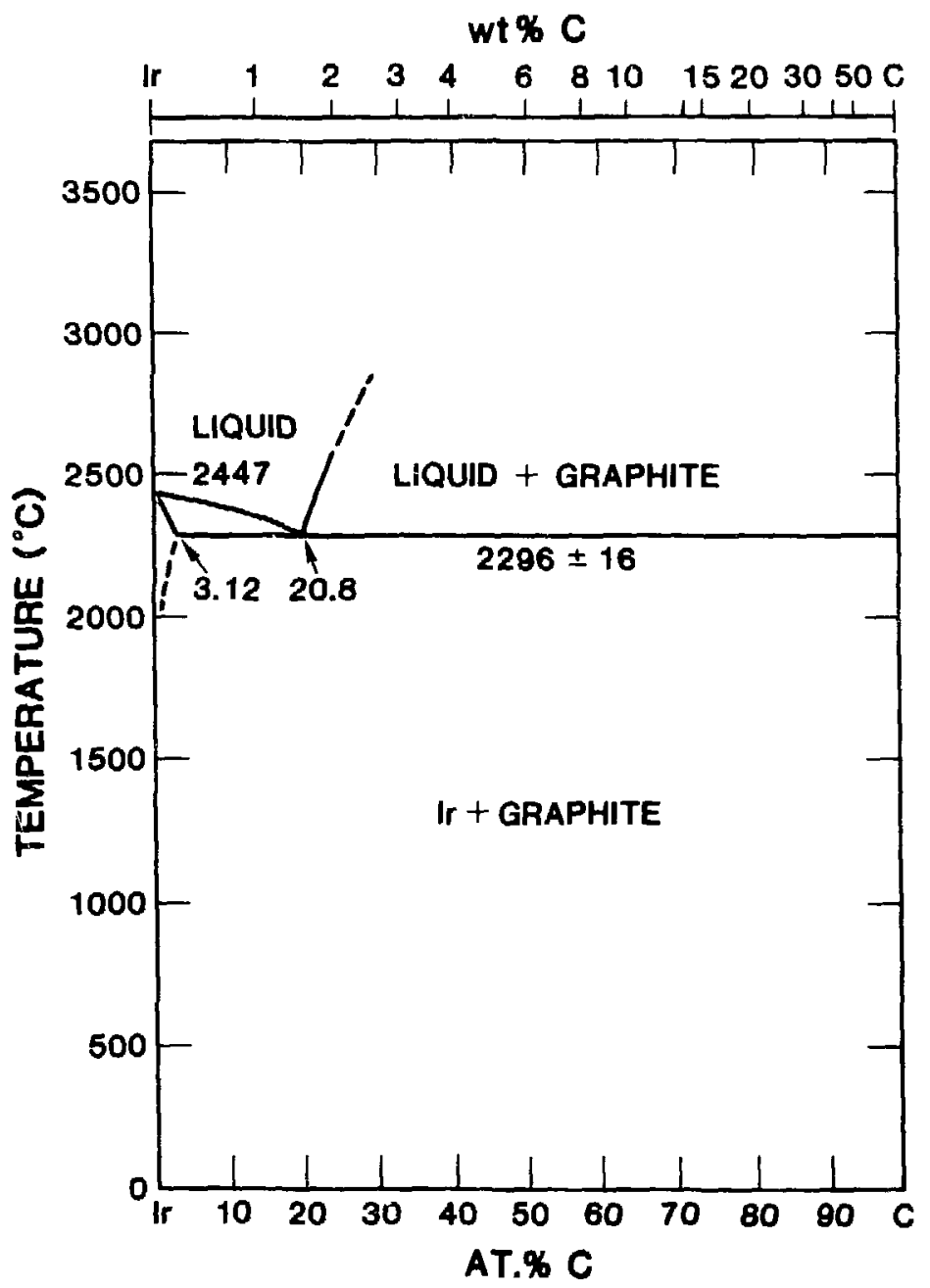

Fig. 3. The Ir-C binary phase diagram according to Ref. 2.

pellet was then reacted in the arc melter, producing a metallic button that appeared homogeneous when examined visually. Slight sputtering occurred during the reaction, which accounted for a small amount of unrecovered material. Because of the nature of this technique, no temperature could be associated with the reaction; however, it is certain that the temperature was considerably higher than the melting points of the components. A specimen cut from the pellet was mounted with a cross sectional view exposed. After polishing, the mounted specimen was electroetched at $15 \mathrm{~V}$ with $\mathrm{HCl}$ in saturated salts. Metallographic examination was performed on the etched specimen. After the metallographic examination, the sample was ground and polished again, then examined by electron microprobe.

In an effort to determine the threshold of reaction for the system, the tests were continued by reacting $\mathrm{PuO}_{2}$ powder with shards of DOP-26 by induction heating. Preparations were made by packing $\mathrm{PuO}_{2}$ into a tungsten cell, then placing the DOP-26 into the PuO 2 . Care was taken to ensure that the DOP-26 shard dic not contact the tungsten cell during heating. As before, temperatures were read using an optical pyrometer sighting on the sample surface through a black-body hole in the cell lid. Reported temperatures reflect a correction for window attenuation. The sample was heated to $1800^{\circ} \mathrm{C}$ in the induction heater under vacuum for 15 minutes. The iridium shard was mounted, polished, and examined by clectron microprobe. An identical preparation was then heated to $2210^{\circ} \mathrm{C}$ for 15 minutes. The reacted DOP-26 shard from this heating was also mounted and examined by microprobe. 


\section{B. Observations}

The metallographic examenation of the are-neled product revealed the presente of awo phases. Flectron mucroprobe showed that the major phase was iridium with the nominal tungsten content. The

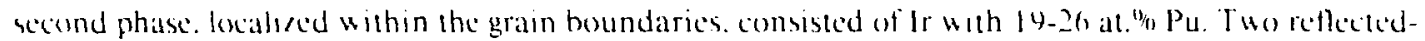
light photomerographs (Fig. 4) show the distribution of the Pu-Ir intermetallic phase within the phatse boundary regions. Figure 5 shows two backscater electron images of al typical grain boundary region examined by microprobe. Also shown in Fig. 5 are $x$-ray dot maps for plutoniun illustrating its distribution within the grain Loundaries. Apparently, the PuO was reduced because no oxtgen wals detected in either phase (the detection limit for oxygen in this system was 0.2 at. $\%$ ).

A visual examination of the reacted $\mathrm{PuO}_{2}$ packing from both induction-heated specimens revealed that it had darkened. indicating partial reciuction that was due to vacuum heating. Figure 6 shows a secondary electron i. age of a typical region within the shard heated to $2210^{\circ} \mathrm{C}$. Also included in Fig. 6 are corresponding $\cdots$ dot maps for plutonium and indium. Microprobe examination of the induction-heated $\mathrm{DC}\left(\mathrm{i}^{\prime}\right.$. $\mathrm{h}$ shards revealed $\mathrm{PuO}$, within the grain boundaries throughout both specimens. No indieations of an intermetallic reaction were found in either case.

\section{Discussion and Conclusions}

An intermetallic phase was formed in the arc-melted sample. The compound Pulr 2 is the most iridium-rich intermetallic compound reported ${ }^{4}$ in the binary systern. The interstitial phase in the arcmelted specimen is believed to be Pulr $r_{2}$ with dissolved iridium.

The induction-heating experiments have shown that no intermetallic reaction occurs at temperatures up to $2210^{\circ} \mathrm{C}$ when the plutonium is present as the oxide. The induction-heating tests do indicate. however, that at temperatures below the onset of reaction, the $\mathrm{PuO}_{2}$ had moved through the grain boundary regions of the DOP-26 matrix. This grain boundary migration indicates that at temperatures at least as low as $1800^{\circ} \mathrm{C}$. plutonium containment may be compromised by the effects of a solid state diffusion mechanism.

\section{AEKNOWLEDGMENTS}

Metallographic and electron microprobe examinations were performed by Ramiro Percyra and Bill Hutchinson. respectively. 


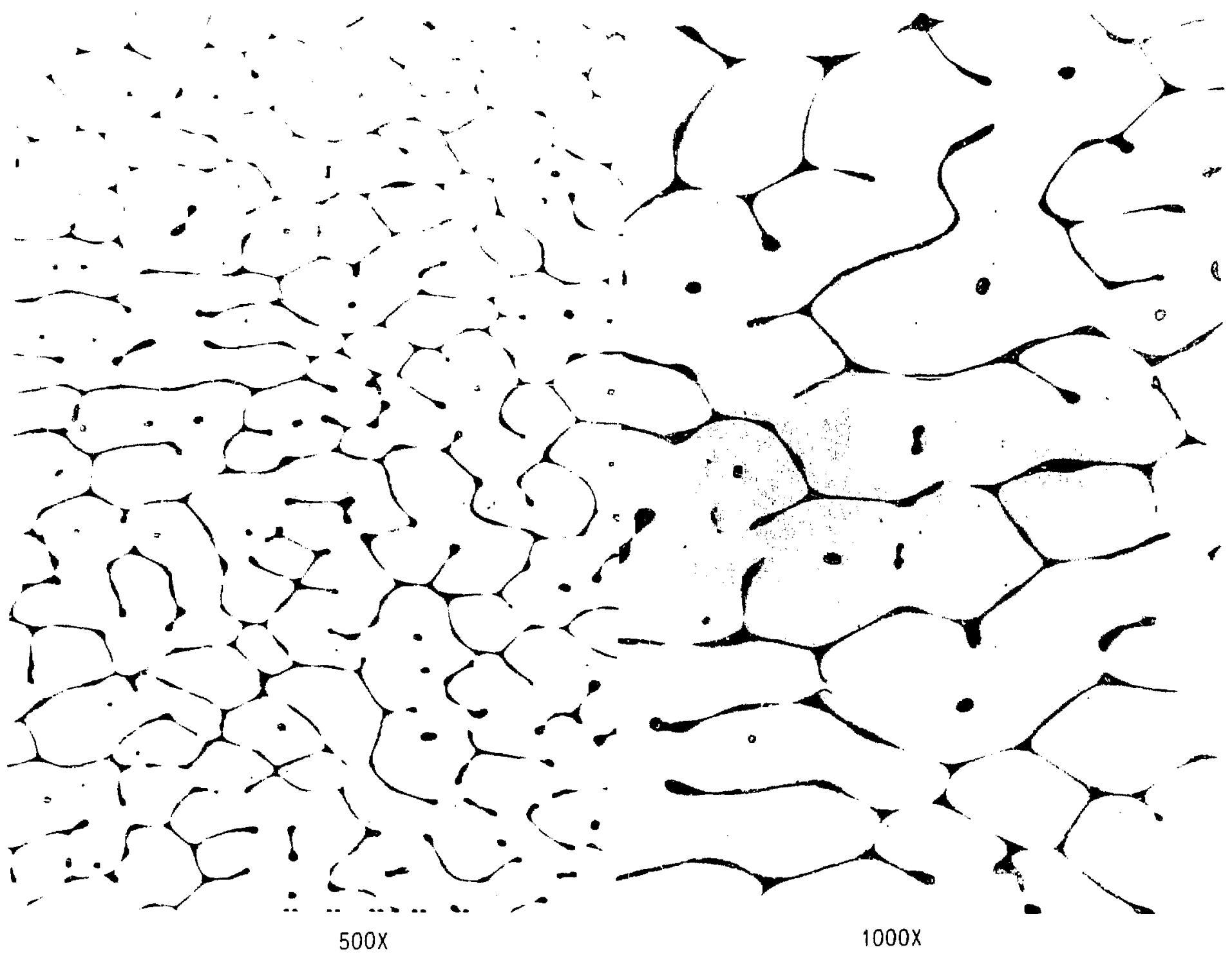

Fig. 4. Photomicrographs of DOP-26 shard reacted with $\mathrm{PuO} \mathrm{O}_{2}$ by arc melting. The matcrial within the grain boundary regiens is the Pu-Ir intermetallic phase. 


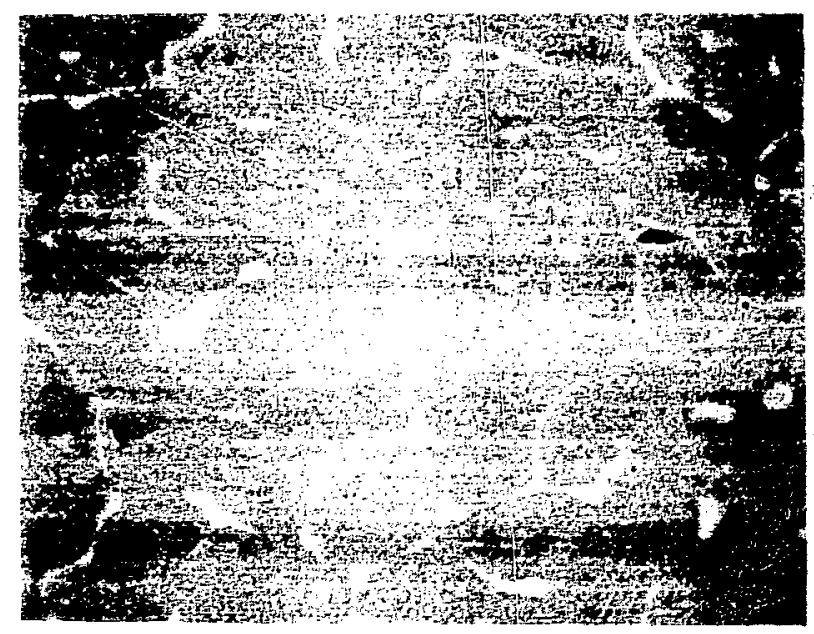

Backsatter telectron image ixily).



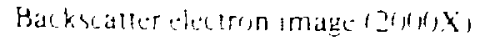

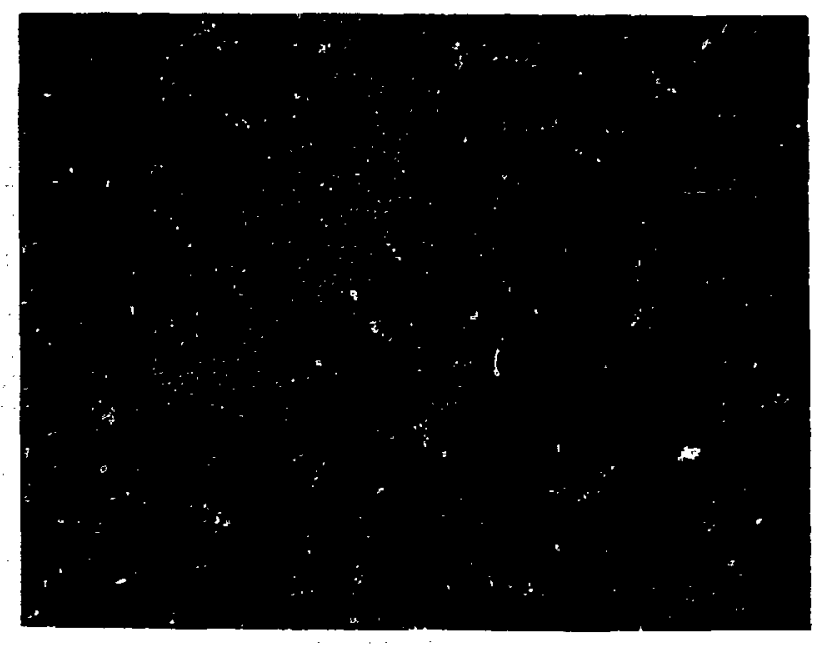

Plutonium $x$-ray dot map $(x()) \times)$.



Plutonium x-rạ: dot map (20)or)X).

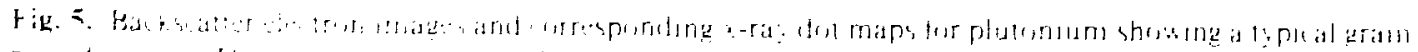






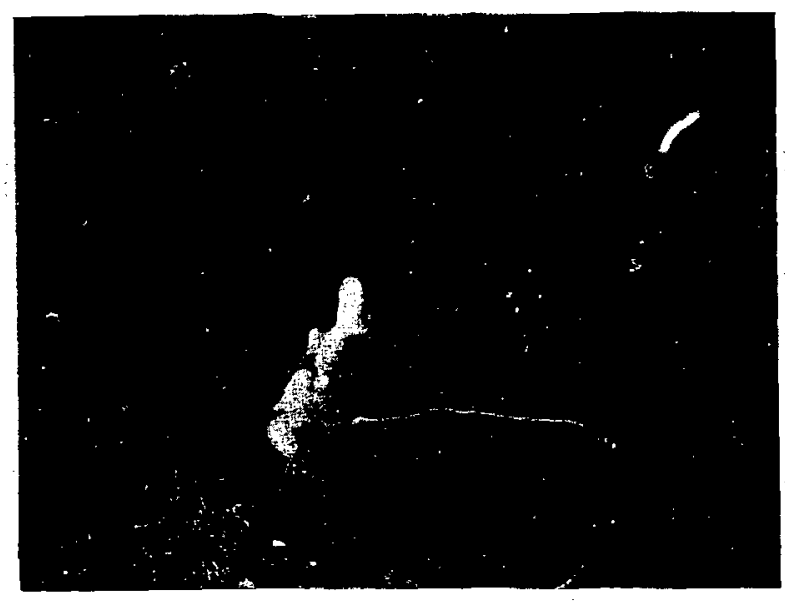

Secondary electron image of an area containing the reduced form of $\mathrm{PuO}_{2}(4000 \mathrm{X})$.

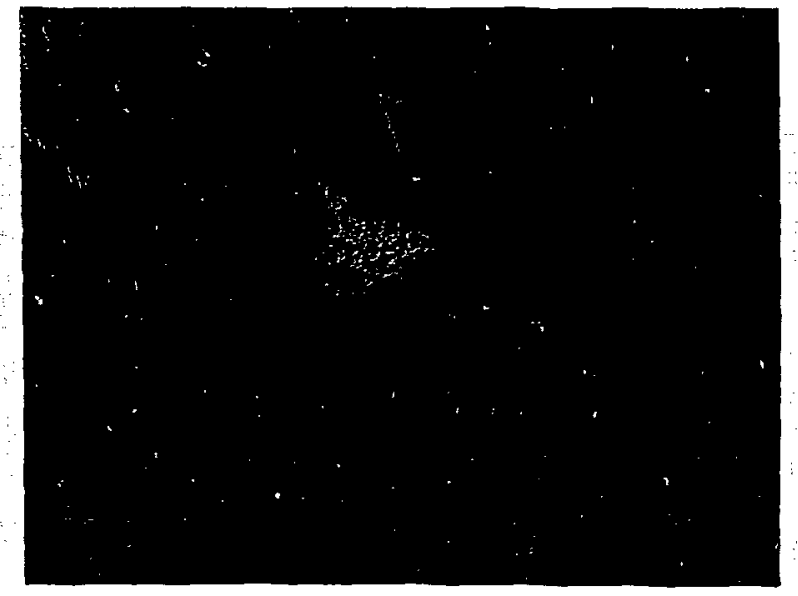

X-ray dot map for plutonium (4000X).

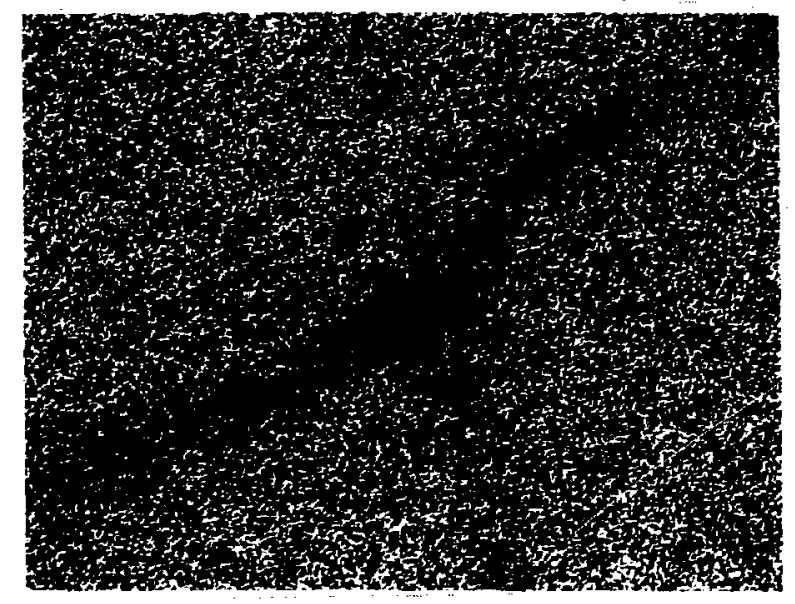

$\mathrm{X}$-ray dot map for iridium (4000X).

Fig. 6. Secondary electron image and corresponding $x$-ray dot maps for plutonium and iridium.

\section{REFERENCES}

I. H. Moissan. C'smpt. Rend. 142 (1906) p. 189.

2. A. E. Vol and I. K. Kagan. Handhook of Binary Hetallic Sistems - Structures and Properties, Iol. 3 (Nauka. Moscow. 1976). p. 788.

3. M. W. Chase. Bulletin of Allon Phase Diagrams. 4(1)(1983). p. 124.

4. R. G. Cope. J. V. Lowe. and D. C. Miller. Atomic Weapons Research Establishment. AWRE-(0-36/6I (1961) p. 18. 